\title{
Proteome-wide Profiling of Cellular Targets Modified by Dopamine Metabolites using a Bio-orthogonally Functionalized Catecholamine
}

Alexander K. Hurben*1, Luke N. Erber ${ }^{1,2}$, Natalia Y. Tretyakova ${ }^{1,2}$, Todd M. Doran ${ }^{1,3}$

${ }^{1}$ Department of Medicinal Chemistry, University of Minnesota, Minneapolis, MN 55455, United States. ${ }^{2}$ Masonic Cancer Center, University of Minnesota, Minneapolis, MN, 55455, United States. ${ }^{3}$ Institute for Translational Neuroscience, University of Minnesota, Minneapolis, MN 55455, United States.

*E-mail: hurbe001@umn.edu

\section{Supporting Information:}

\section{Table of Contents}

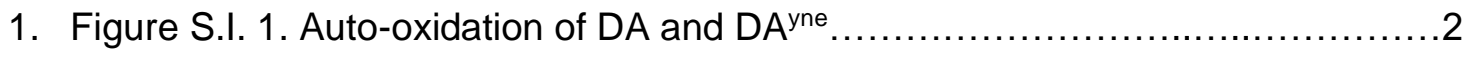

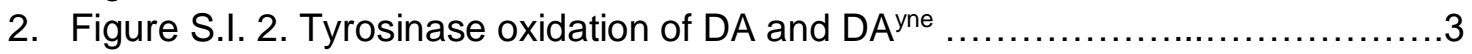

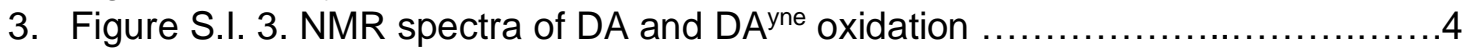

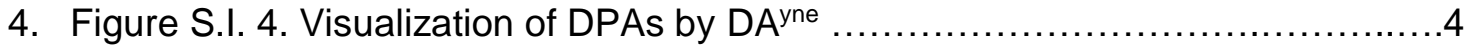

5. Figure S.I. 5. DA and $D A^{\text {yne }}$ treatment induce melanin formation in cellular debris..5

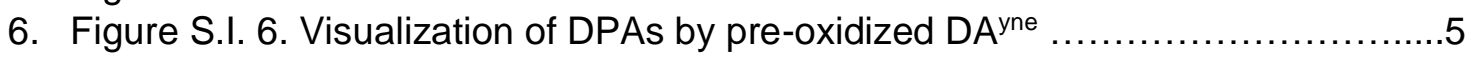

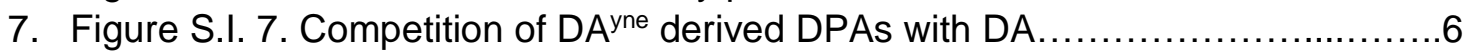

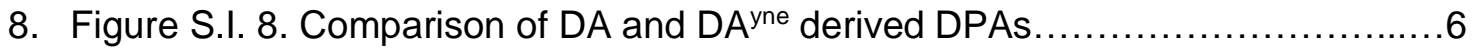

9. Figure S.I. 9. Azide functionalized agarose beads capture DA ${ }^{\text {yne }}$ induced DPAs....7

10. Figure S.I. 10. Proteomic enrichment with is $D^{\text {yne }}$ reproducible .................... 8

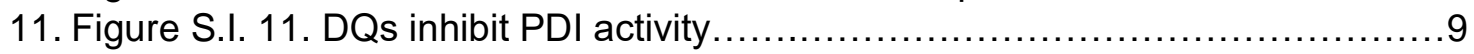

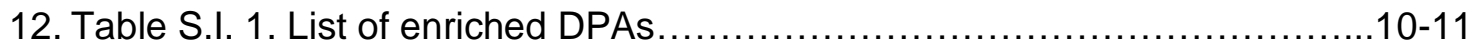

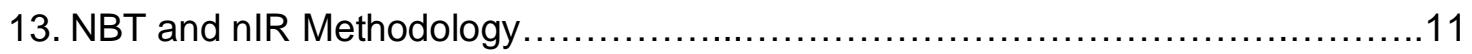

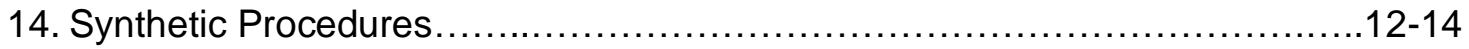

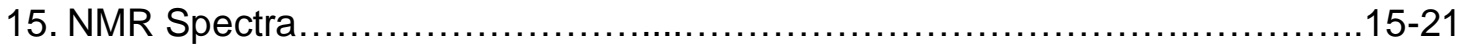

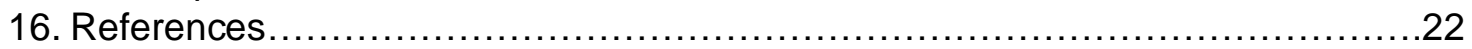




\section{Supplementary Figures}

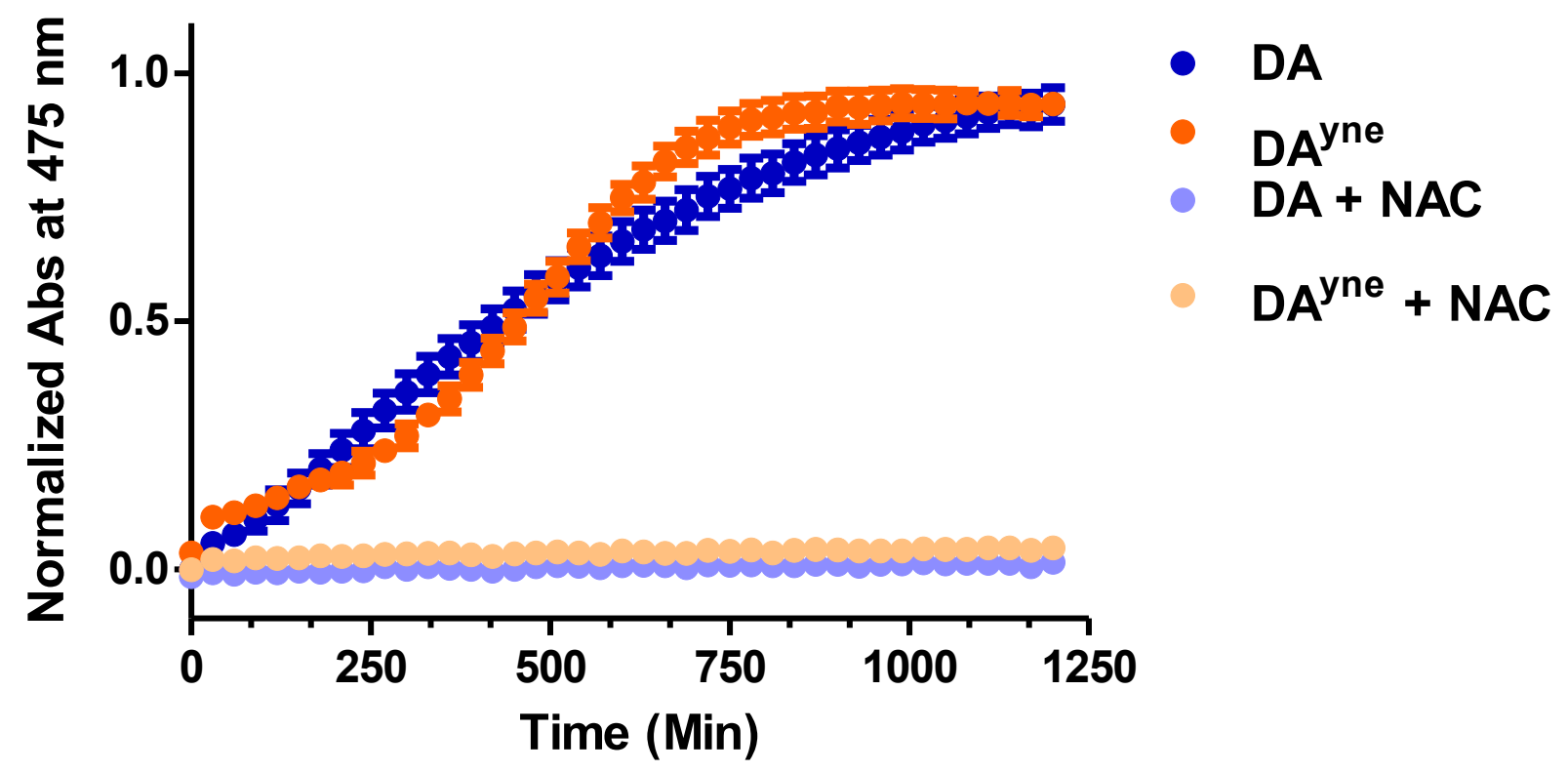

S.I. 1. Auto-oxidation of DA and $D A^{y n e}$. $D A$ and $D A^{y n e}(50 \mu M)$ were incubated at $37^{\circ} \mathrm{C}$ in $P B S$, $\mathrm{pH} 7.4$ in the presence or absence of $1 \mathrm{mM} \mathrm{NAC}$. Absorbance at $475 \mathrm{~nm}$, indicative of aminochrome formation, was measured at $30 \mathrm{~min}$ intervals over the course of $20 \mathrm{hrs}$. Data are represented as mean \pm SEM from three replicates.
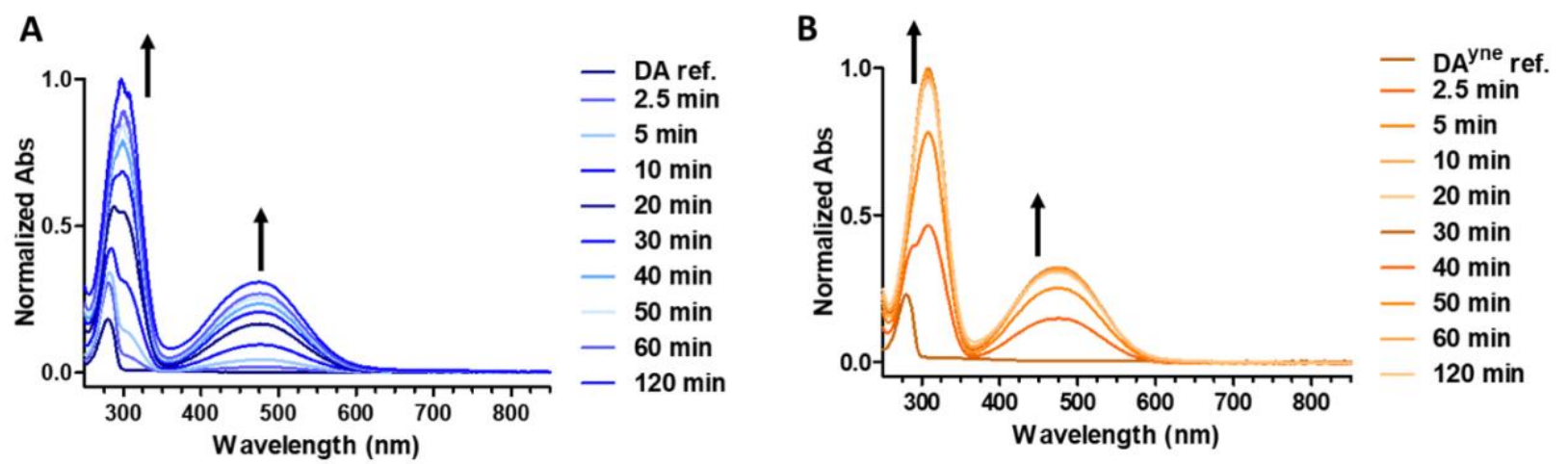

S.I. 2. Tyrosinase oxidation of $D A$ and $D A^{y n e}$. TY (300 units) was incubated with $150 \mu M D A$ (A) or $\mathrm{DA}^{\mathrm{yne}}(\mathrm{B})$ and the reaction was monitored via UV-Vis. The increase at $475 \mathrm{~nm}$ indicates successful oxidation of the substrate by TY to its corresponding aminochrome. 


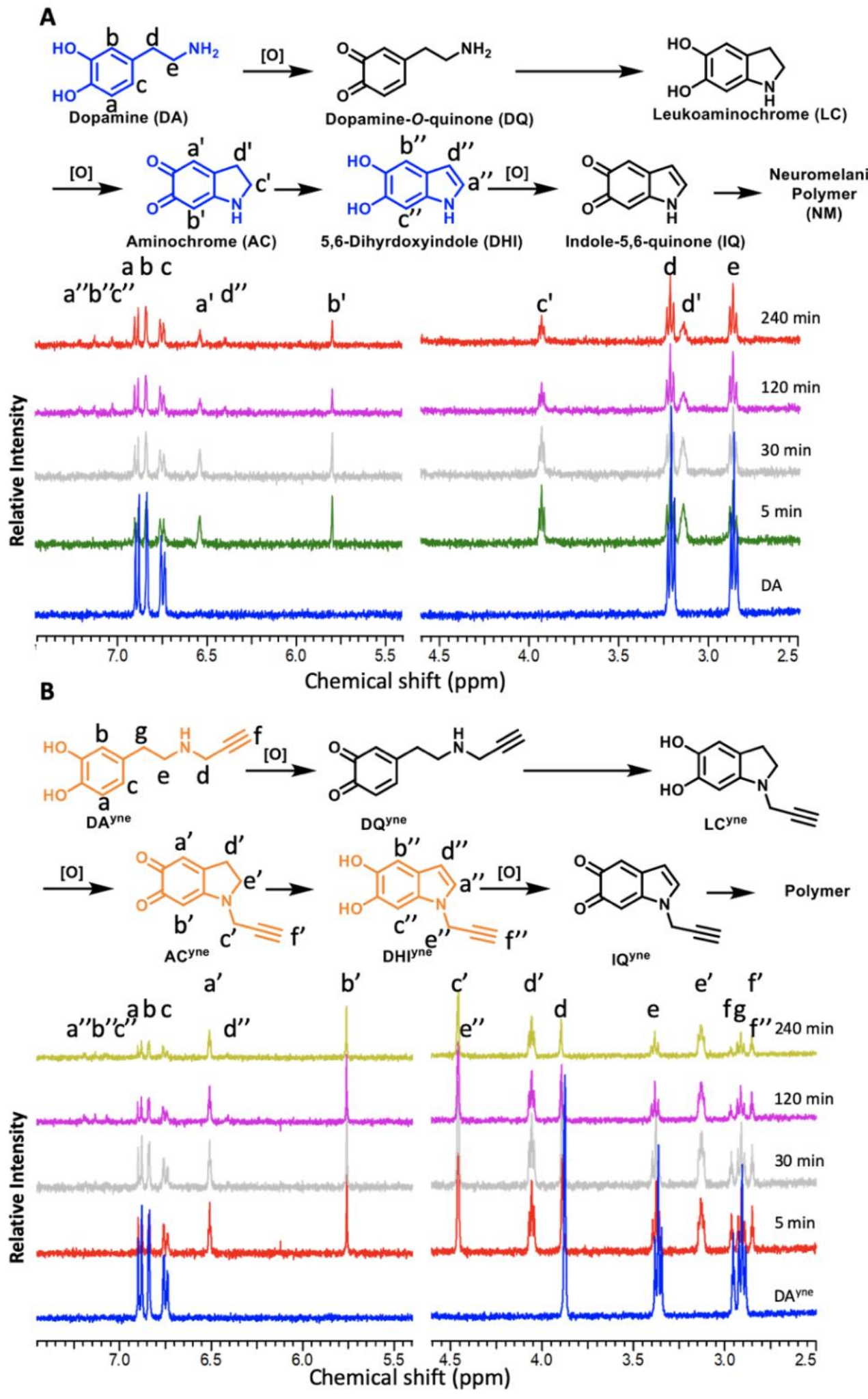

S.I. $3 \mathrm{NMR}$ spectra of reaction time course between $1 \mathrm{mM} \mathrm{DA}(\mathrm{A})$ or $\mathrm{DA}^{\mathrm{yne}}(\mathrm{B})$ and $1 \mathrm{mM} \mathrm{NaIO}_{4}$ in PBS pH 7.4. Labels above proton resonances denote corresponding molecular labels. Water solvent peak was removed for clarity 

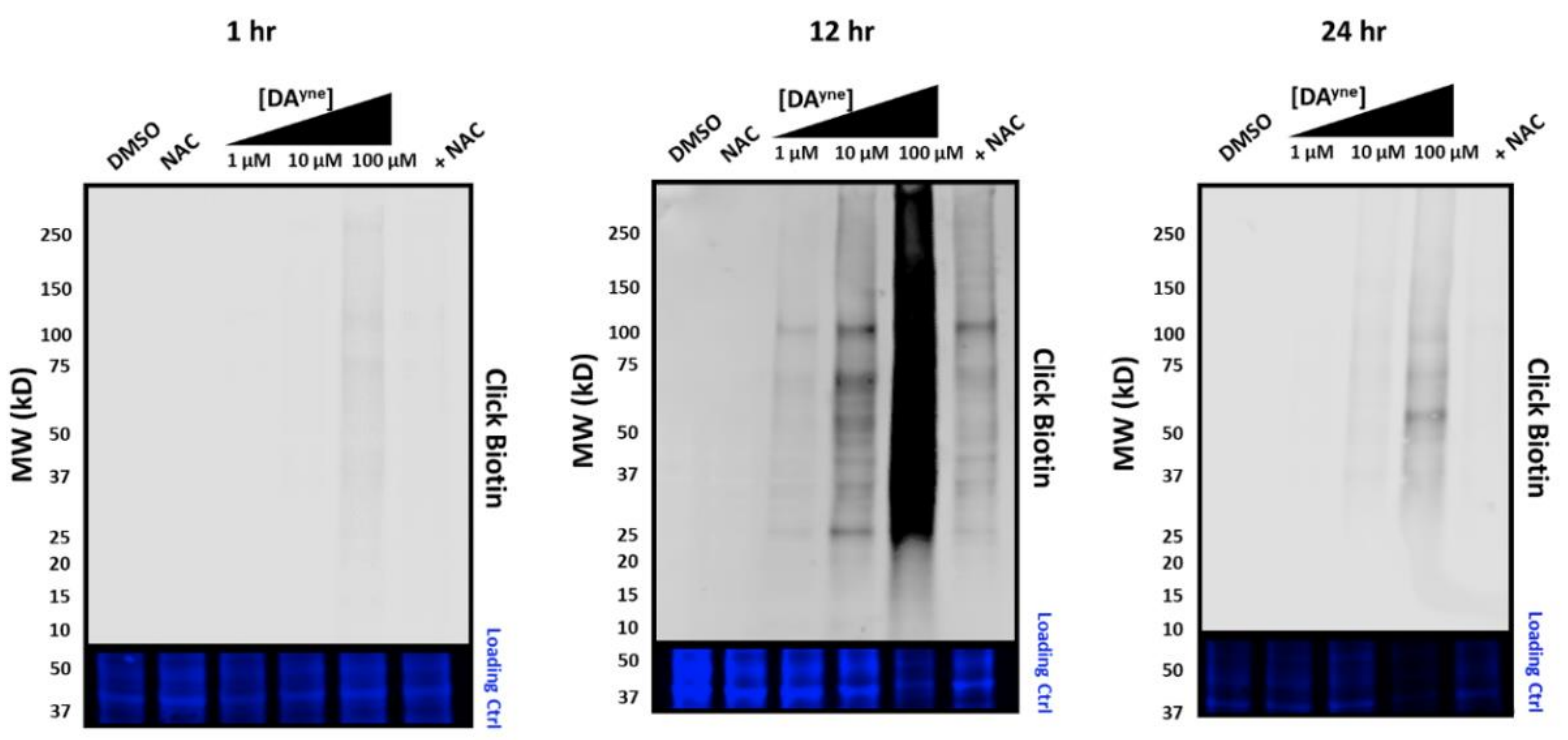

S.I. 4. Visualization of DPAs by $D A^{\text {yne }}$. Representative nitrocellulose blots following incubation of SH-SY5Y cells with DMSO, $2.5 \mathrm{mM}$ NAC, $1 \mu \mathrm{M}, 10 \mu \mathrm{M}, 100 \mu \mathrm{M}$, or $100 \mu \mathrm{M} \mathrm{DA}^{\text {yne }}$ and 2.5 $\mathrm{mM}$ NAC for the allotted time, lysis and ensuing CuAAC click reaction with biotin azide. Top: $800 \mathrm{~nm}$ channel following incubation with SA800. Bottom: $700 \mathrm{~nm}$ channel following revert total protein stain. Brightness and contrast between the blots are equivalent.

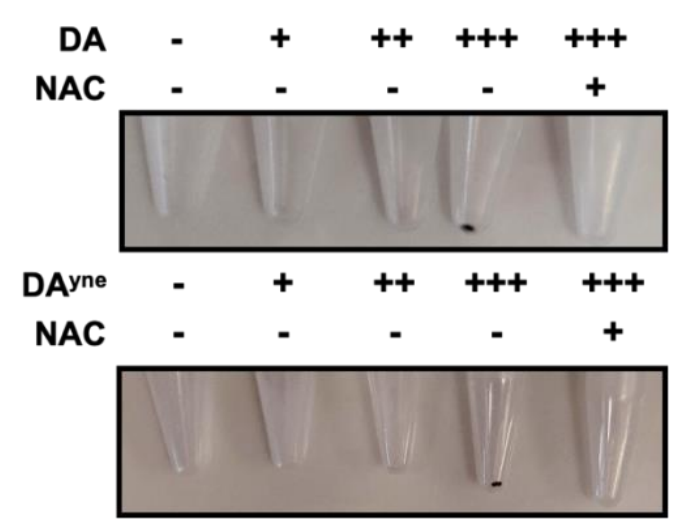

S.I. 5. DA and $D A^{\text {yne }}$ treatment induce melanin formation in cellular debris. Photographed tubes contain cellular debris pellet following lysis. SH-SY5Y cells were treated with DMSO, $2.5 \mathrm{mM}$ NAC, $1 \mu \mathrm{M}, 10 \mu \mathrm{M}, 100 \mu \mathrm{M}$, or $100 \mu \mathrm{M}$ DA/DA ${ }^{\text {yne }}$ and $2.5 \mathrm{mM}$ NAC as indicated. Black debris was observed in $100 \mu \mathrm{M}$ treatments, which presumably are melanin polymers and aggregates. 


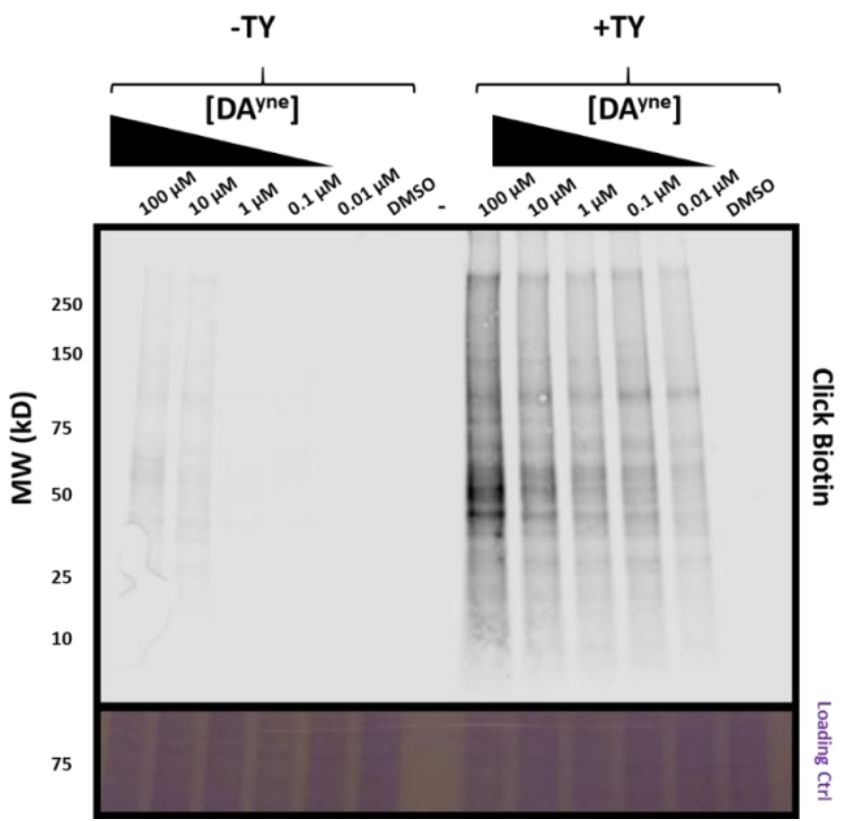

S.I. 6. Visualization of DPAs by pre-oxidized DA ${ }^{\text {yne }}$. A) Representative nitrocellulose blot following 1-hour incubation of SH-SY5Y cells with respective $\mathrm{DA}^{\mathrm{yne}}$ concentration in the presence or absence of 600 units of TY, lysis and ensuing CuAAC click reaction with biotin azide. Top: $800 \mathrm{~nm}$ channel following incubation with SA800. Bottom: Coomassie blue stain to confirm equal protein loading. 


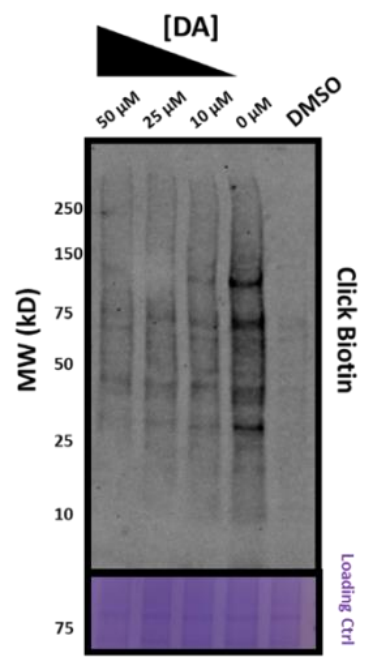

S.I. 7. Competition of $D A^{y n e}$ derived DPAs with DA. Representative nitrocellulose blot of three independent experiments following 1-hour incubation of SH-SY5Y cells with $10 \mu \mathrm{M} D A^{\text {yne }}$ after a 30-min pre-incubation at the specified DA concentration in the presence of 600 units of TY, lysis and ensuing CuAAC click reaction with biotin azide. Top: $800 \mathrm{~nm}$ channel following incubation with SA800. Bottom: Coomassie blue stain to confirm equal protein loading.
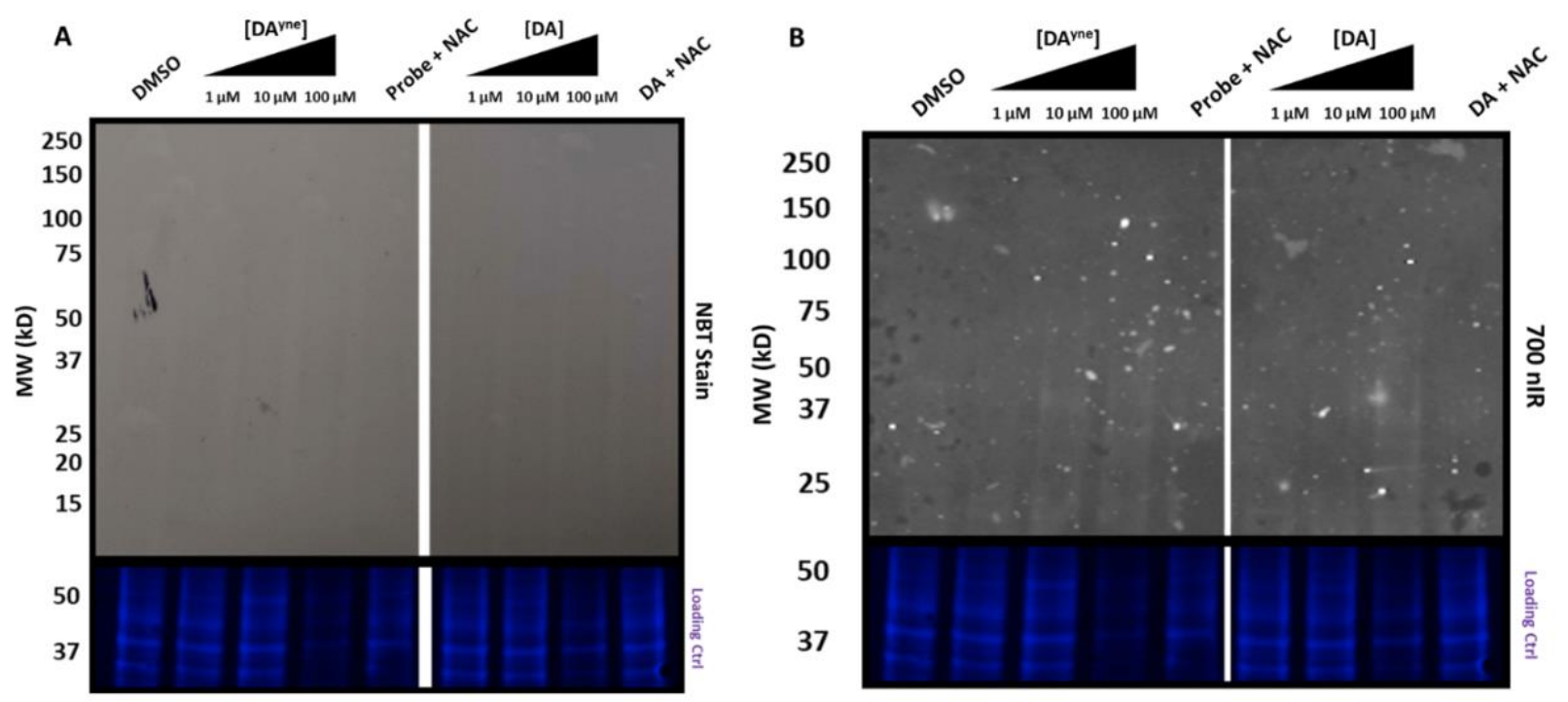

S.I. 8. Comparison of DA and DA ${ }^{\text {yne }}$ derived DPAs. (A) DPAs detection through NBT staining. Representative nitrocellulose blot following 1 -hour incubation of SH-SY5Y cells with respective concentration of DA or DA ${ }^{\text {yne }}$ in the presence of 600 units of TY, lysis and NBT staining. Top: NBT stain; purple bands mark DPAs. Bottom: $700 \mathrm{~nm}$ channel following revert total protein stain. (B) DPAs detection via nIR florescence. Representative nitrocellulose blot following 1 hour incubation of SH-SY5Y cells with respective concentration of DA or DA ${ }^{\text {yne }}$ in the presence of 600 units of TY, lysis and nIR imaging. Top: $700 \mathrm{~nm}$ channel imaging immediately after membrane transfer; white bands mark DPAs. Bottom: $700 \mathrm{~nm}$ channel following revert total protein stain. 


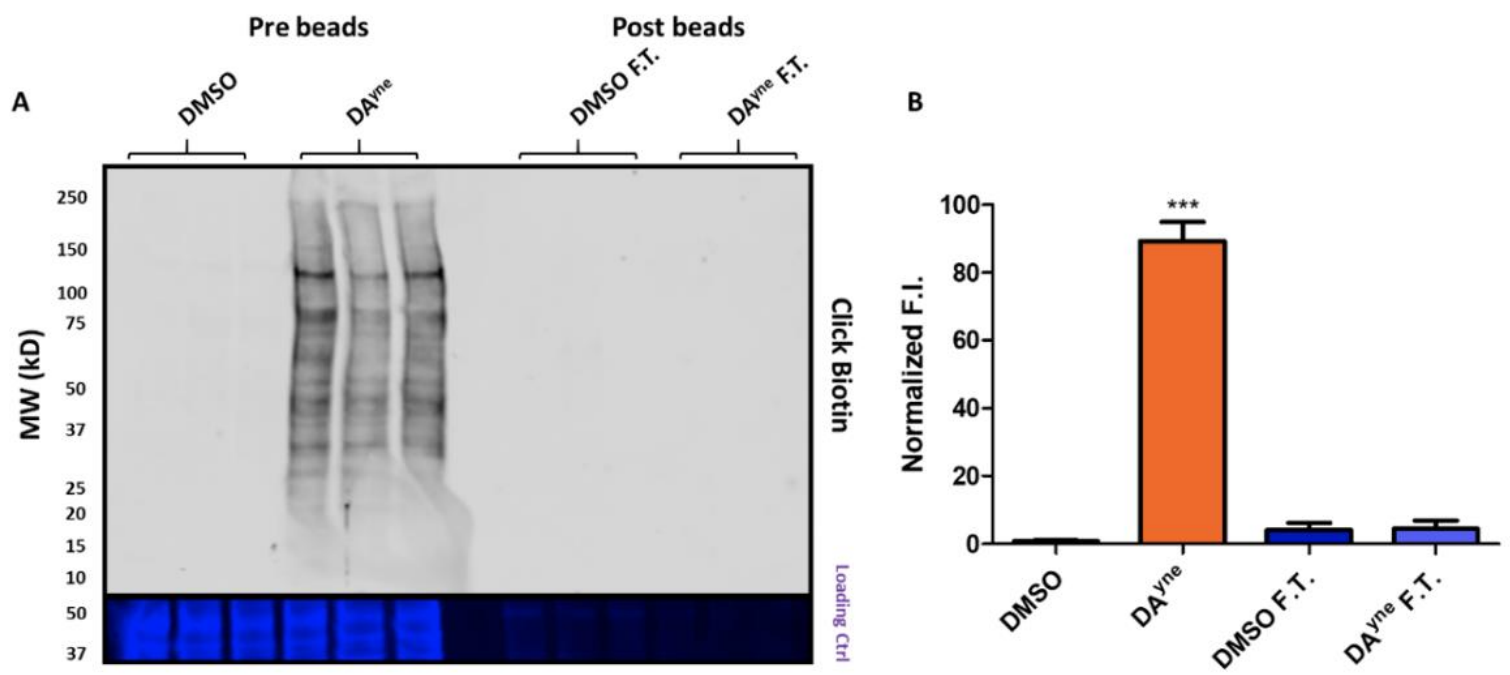

S.I. 9. Azide functionalized agarose beads capture DA ${ }^{\text {yne }}$ induced DPAs. (A) Nitrocellulose blot following incubation of SH-SY5Y cells with DMSO, $10 \mu \mathrm{M}$ DA yne for $12 \mathrm{hrs}$, lysis and ensuing $\mathrm{Cu}$ click reaction with biotin azide pre or post reaction with azide beads. F.T. denotes flowthrough. Top: $800 \mathrm{~nm}$ channel following incubation with SA800. Bottom: $700 \mathrm{~nm}$ channel following revert total protein stain. (B) Quantification of DPAs. Fluorescence intensity (F.I.) of SA800 for each treatment was normalized by total protein through the revert stain. Data are represented as mean \pm SEM from three replicates. Data were analyzed via a one-way ANVOA and an unpaired t-test to DMSO $\left({ }^{* * *} \mathrm{p}<0.001\right)$. 


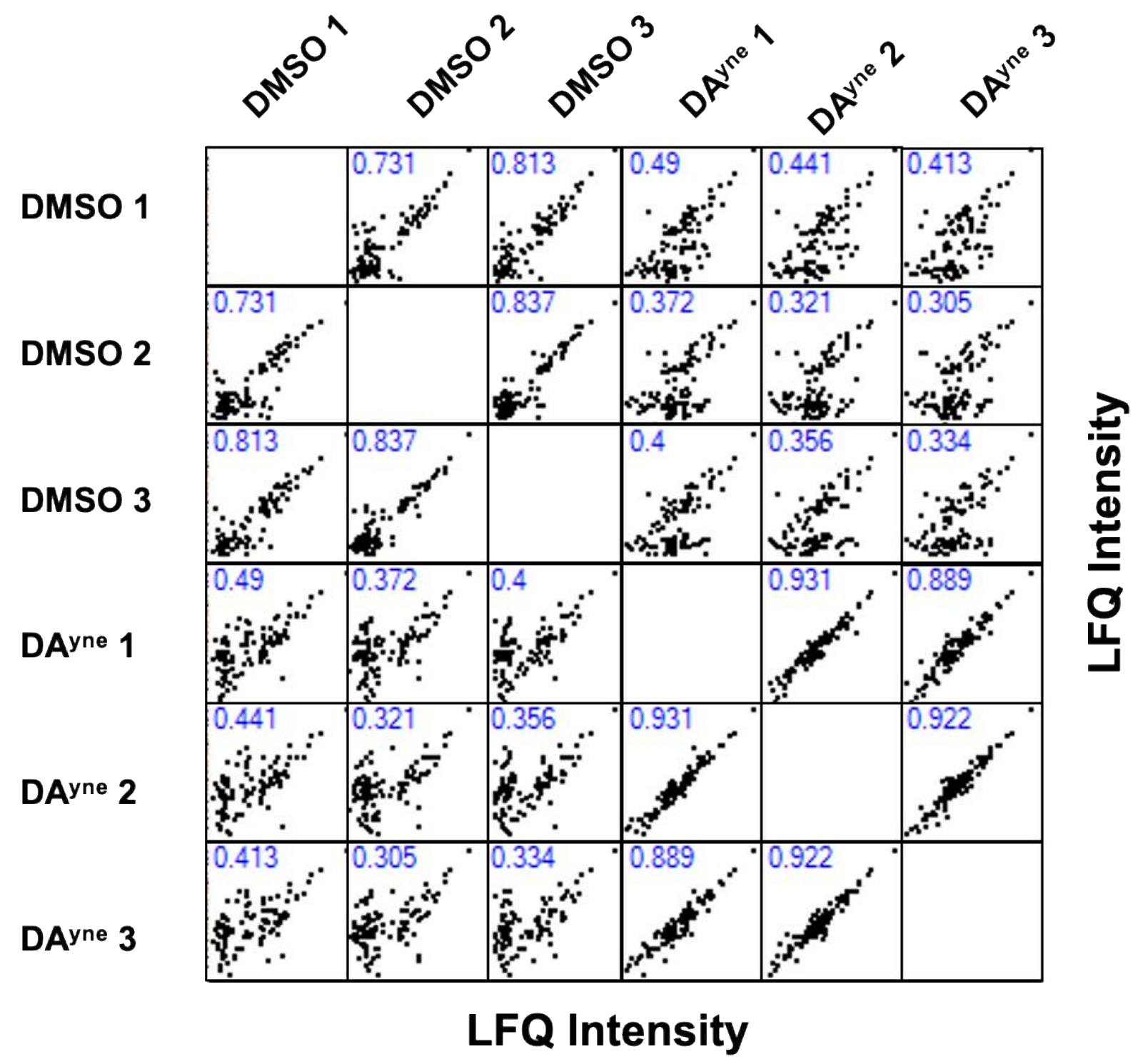

S.I. 10. Proteomic enrichment with is $D A^{\text {yne }}$ reproducible. Correlation plots show the intensity of label free quantitation (LFQ) values for a given treatment condition on the $X$ and $Y$ axis. Identified proteins are represented as black squares. The $\mathrm{R}^{2}$ value for each comparison in written in blue. The Perseus software suite (version 1.6.6.0) was used generate this plot. 


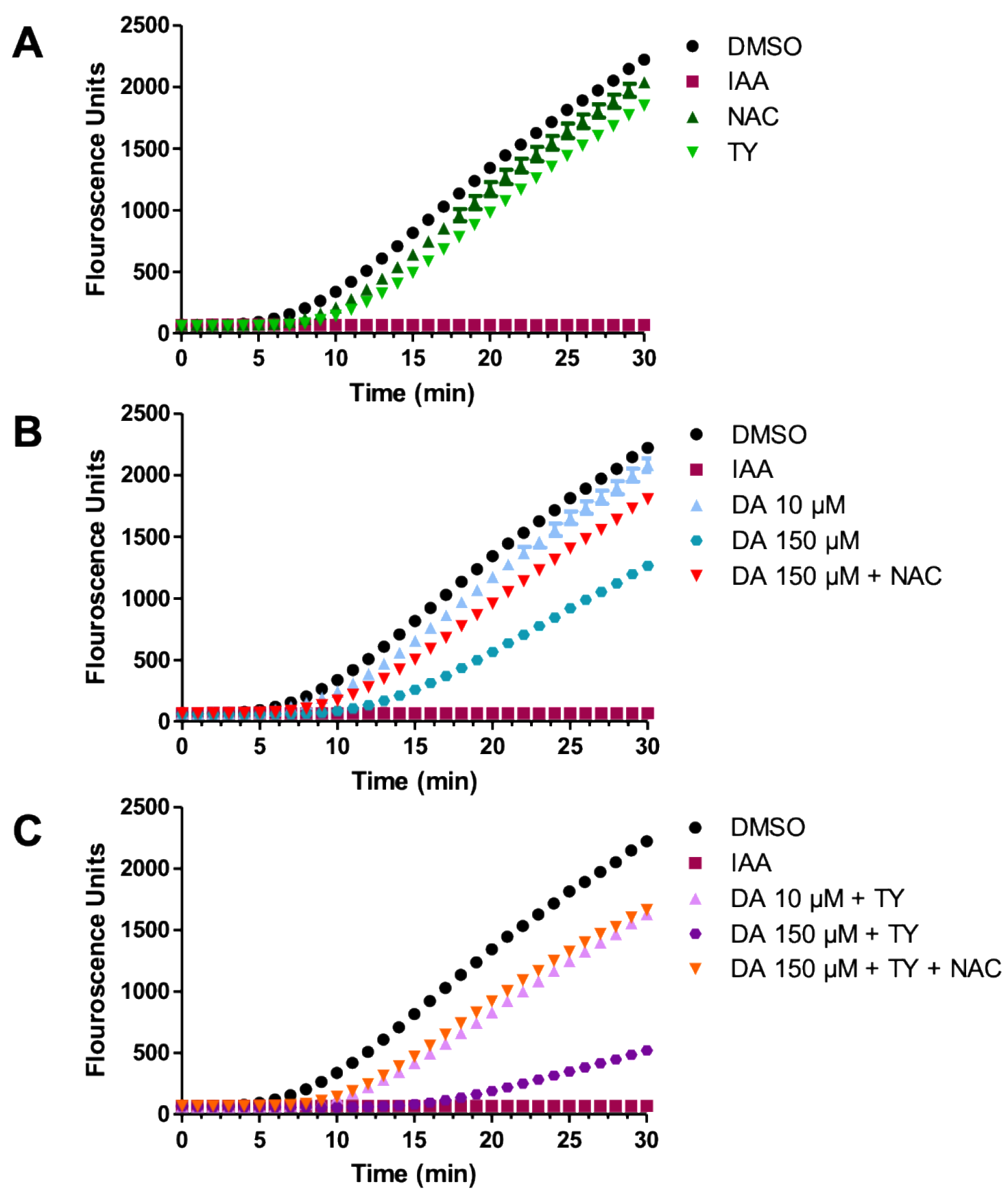

S.I. 11. DQs inhibit PDI activity. Plots show raw fluorescence units, indicative of PDI activity, measured every 60 seconds at 440/490 Ex/Em over the course of the assay. Percent activity is calculated from the linear region of assay and normalized to DMSO. (A) PDI activity following incubation with negative controls; DMSO, $1 \mathrm{mM} \mathrm{NAC}$, and TY flow through and positive control IAA. (B) PDI activity following incubation with indicated concentrations of DA. (C) PDI activity following incubation with indicated concentrations of DA pre-oxidized with TY. 
S.I. Table 1. List of enriched DPAs. The third column reports the T-test pValue to assess enrichment of DPAs. The fourth column reports the difference between the mean LFQ intensity between DA ${ }^{\text {yne }}$ and DMSO treated groups. Data is representative of 3 biological replicates from each treatment condition. An input of $100 \mu \mathrm{g}$ of protein lysate was used to prepare each sample.

\begin{tabular}{|c|c|c|c|c|}
\hline Protein & Gene & $\begin{array}{l}\text { Negative } \\
\text { Log } p\end{array}$ & \multicolumn{2}{|c|}{$\begin{array}{c}\text { Difference } \\
\left(\text { DA }^{\text {yne }}-\text { DMSO) }\right.\end{array}$} \\
\hline $\begin{array}{l}\text { Poly }(\mathrm{rC}) \text {-binding protein } 1 \\
\text { Bifunctional glutamate/proline- } \\
\text {-tRNA ligase }\end{array}$ & PCBP1 & 4.608 & 5.096 & $\begin{array}{l}\text { microtubule binding } \\
\text { Fe binding, mRNA splicing factor, } \\
\text { ribonucleoprotein, serine protease }\end{array}$ \\
\hline Dopamine beta-hydroxylase & $\mathrm{DBH}$ & 4.288 & 3.200 & conversion of dopamine to noradrenaline \\
\hline $\begin{array}{l}\text { Cofilin-1 } \\
\text { E3 SUMO-protein ligase } \\
\text { RanBP2 } \\
\text { Ubiquitin carboxyl-terminal } \\
\text { hydrolase } 10\end{array}$ & $\begin{array}{l}\text { CFL1 } \\
\text { RANBP2 } \\
\text { USP10 }\end{array}$ & 3.785 & 4.738 & $\begin{array}{l}\text { G-protein modulator } \\
\text { cysteine protease }\end{array}$ \\
\hline E3 ubiquitin-protein ligase & HUWE1 & 3.463 & 3.146 & ubiquitin-protein ligase \\
\hline $\begin{array}{l}\text { Neuromodulin } \\
\text { Mitochondrial antiviral- } \\
\text { signaling protein } \\
\text { Serine/arginine-rich splicing } \\
\text { factor } 2\end{array}$ & $\begin{array}{l}\text { GAP43 } \\
\text { MAVS } \\
\text { SRSF2 }\end{array}$ & $\begin{array}{r}3.339 \\
3.197 \\
3.149\end{array}$ & $\begin{array}{l}2.286 \\
2.385\end{array}$ & $\begin{array}{l}\text { nerve growth } \\
\text { innate immune defense against viruses } \\
\text { mRNA splicing factor }\end{array}$ \\
\hline $\begin{array}{l}\text { Src substrate cortactin } \\
\text { Microtubule-associated protein } \\
\end{array}$ & $\begin{array}{l}\text { CTTN } \\
\text { MAP2 }\end{array}$ & $\begin{array}{l}3.112 \\
3.074\end{array}$ & $\begin{array}{l}3.004 \\
2.793\end{array}$ & $\begin{array}{l}\text { developmental protein } \\
\text { basic helix-loop-helix transcription factor, } \\
\text { non-motor actin binding protein } \\
\text { microtubule bindina }\end{array}$ \\
\hline Protein PRRC2C & PRRC2C & 3.002 & 2.729 & nuclease, transcription factor \\
\hline Pyruvate kinase & PKM & 2.997 & 3.488 & key role in glycolysis \\
\hline $\begin{array}{l}\text { Nestin } \\
\text { Dihydropyrimidinase-related } \\
\text { protein } 1\end{array}$ & $\begin{array}{l}\text { NES } \\
\text { CRMP1 }\end{array}$ & $\begin{array}{l}2.913 \\
2.821\end{array}$ & $\begin{array}{l}3.431 \\
4.442\end{array}$ & $\begin{array}{l}\text { brain development } \\
\text { metalloprotease }\end{array}$ \\
\hline $\begin{array}{l}\text { Prefoldin subunit } 3 \\
\text { Eukaryotic peptide chain } \\
\text { release factor GTP-binding } \\
\text { subunit } \\
\text { Uncharacterized protein } \\
\text { C11orf96 } \\
\text { Sarcoplasmic/endoplasmic } \\
\text { reticulum calcium ATPase } 2 \\
\text { Immunity-related GTPase } \\
\text { family Q protein }\end{array}$ & $\begin{array}{l}\text { GSPT1 } \\
\text { C11orf96 } \\
\text { ATP2A2 } \\
\text { IRGQ }\end{array}$ & $\begin{array}{l}2.799 \\
2.785 \\
2.774 \\
2.757\end{array}$ & $\begin{array}{l}2.331 \\
2.549 \\
2.087\end{array}$ & $\begin{array}{l}\text { chaperone } \\
\text { G-protein, hydrolase, translation elongation } \\
\text { factor, translation initiation factor, translation } \\
\text { release factor }\end{array}$ \\
\hline Calponin-3 & CNN3 & 2.751 & 2.600 & non-motor actin binding protein \\
\hline $\begin{array}{l}\text { Fatty acid synthase } \\
\text { Calcium-regulated heat-stable } \\
\text { protein } 1\end{array}$ & $\begin{array}{l}\text { FASN } \\
\text { CARHSP1 }\end{array}$ & $\begin{array}{l}2.714 \\
2.650\end{array}$ & 3.354 & $\begin{array}{l}\text { acyltransferase, dehydrogenase, esterase, } \\
\text { ligase, methyltransferase }\end{array}$ \\
\hline La-related protein 1 & LARP1 & 2.639 & 2.120 & ribonucleoprotein \\
\hline $\begin{array}{l}\text { Tubulin alpha- } 1 \mathrm{~A} \text { chain } \\
\text { Microtubule-associated protein } \\
1 \mathrm{~B} \\
\text { Epidermal growth factor } \\
\text { receptor substrate } 15\end{array}$ & $\begin{array}{l}\text { TUBA1A } \\
\text { MAP1B }\end{array}$ & $\begin{array}{l}2.334 \\
2.248\end{array}$ & $\begin{array}{l}2.857 \\
4.199\end{array}$ & $\begin{array}{l}\text { tubulin } \\
\text { non-motor microtubule binding protein } \\
\text { G-protein modulator, calcium-binding protein, } \\
\text { membrane traffic protein }\end{array}$ \\
\hline Alpha-internexin & INA & 2.014 & 2.102 & morphogenesis of neurons \\
\hline
\end{tabular}




\begin{tabular}{|c|c|c|c|c|}
\hline \multirow[b]{2}{*}{ Protein disulfide-isomerase A3 } & \multirow[b]{2}{*}{ PDIA3 } & & & \multirow[b]{2}{*}{$\begin{array}{l}\text { catalyzes the formation, breakage and } \\
\text { rearrangement of disulfide bonds }\end{array}$} \\
\hline & & 2.006 & 4.148 & \\
\hline $\begin{array}{l}\text { Clathrin heavy chain } 1 \\
\text { Echinoderm microtubule- } \\
\text { associated protein-like } 4\end{array}$ & CLTC & 1.810 & & \multirow{4}{*}{$\begin{array}{l}\text { vesicle coat protein } \\
\text { microtubule cytoskeleton } \\
\text { actin filament binding } \\
\text { catalyzes the formation, breakage and } \\
\text { rearrangement of disulfide bonds } \\
\text { catalyzes the formation, breakage and } \\
\text { rearrangement of disulfide bonds }\end{array}$} \\
\hline Filamin-A & FLNA & 1.466 & 2.613 & \\
\hline Protein disulfide-isomerase A6 & PDIA6 & 1.361 & 3.028 & \\
\hline Protein disulfide-isomerase & $\mathrm{P} 4 \mathrm{HB}$ & 1.175 & 2.238 & \\
\hline
\end{tabular}

\section{Additional Methodology}

NBT Staining ${ }^{1}$

Nitrocellulose blots were prepared previously described. Immediately following transfer, blots were washed twice with water and incubated with a $0.75 \mathrm{mM}$ nitro blue tetrazolium (NBT), $2 \mathrm{M}$ potassium glycinate buffer ( $\mathrm{pH} \mathrm{10)}$ in the dark for 45 mins at room temp. The NBT solution was removed and the blot was washed with $160 \mathrm{mM}$ sodium borate solution two times. The blot was further incubated in the $160 \mathrm{mM}$ sodium borate overnight. The blot was then washed with water and imaged with an optical camera.

\section{nIR Detection ${ }^{2}$}

Nitrocellulose blots were prepared previously described. Immediately following transfer, blots were washed twice with water and imaged with a Licor Odyssey CLX. 


\section{Synthetic Procedures}

\section{General Procedures}

Chemical reactions were conducted in a fumehood with oven-dried glassware under an argon atmosphere unless otherwise stated. Thin-layer chromatography (TLC) was performed with analtech silica uniplates and visualized under $254 \mathrm{~nm}$ UV light. Column chromatography was conducted with 60 mesh silica gel. A Buchi R-200 rotary evaporator and V-100 vacuum pump were used to remove solvent. NMR spectra were taken on a $400 \mathrm{MHz}$ Varian spectrometer. HRMS spectra were taken on a Burker ESI-BioTOF II instrument and internally calibrated with PEG 300 .

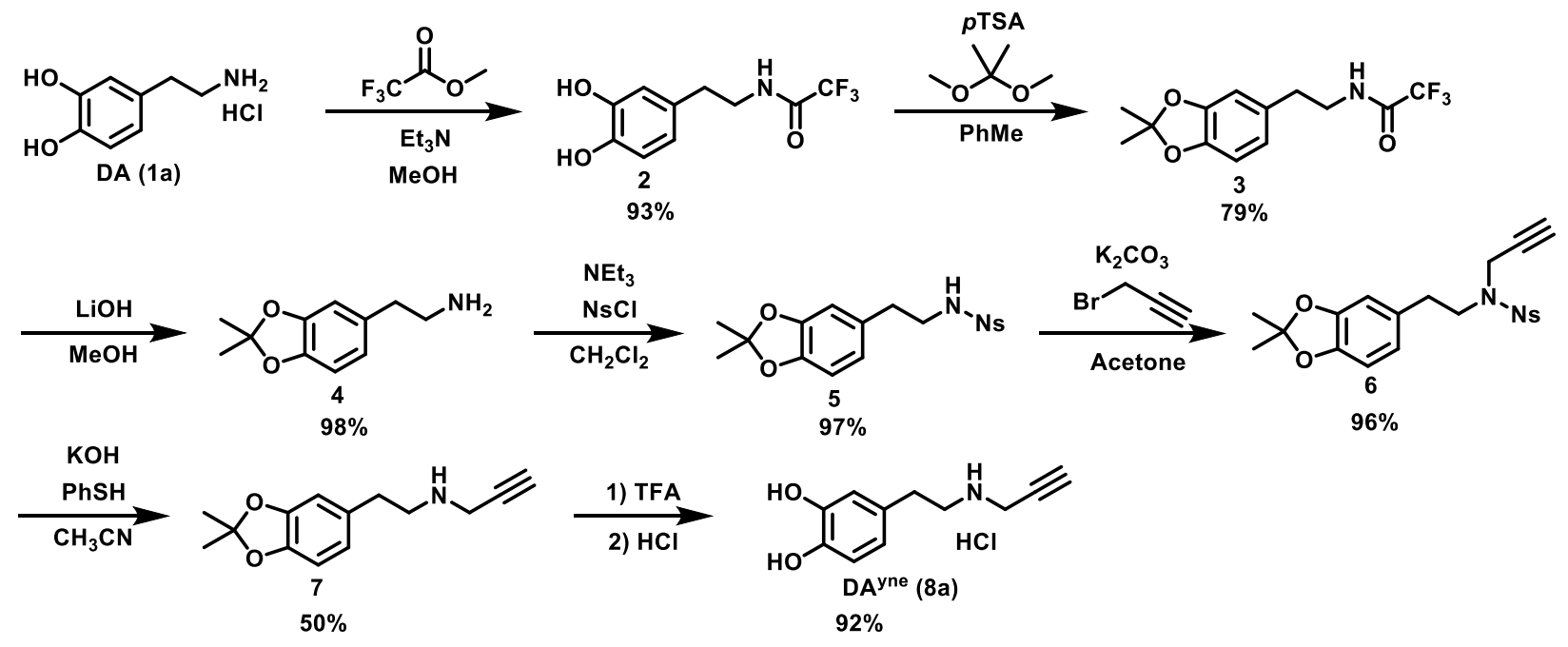

\section{S.I. Scheme 1 Synthesis of DA $A^{\text {yne }}$}

N-(3,4-dihydroxyphenethyl)-2,2,2-trifluoroacetamide 2.

Dopamine $\mathrm{HCl}(3.42 \mathrm{~g}, 18 \mathrm{mmol}, 1 \mathrm{eq})$ was dissolved into $100 \mathrm{~mL}$ of $\mathrm{MeOH}$. The resultant solution was purged with argon for 20 minutes, then methyl trifluoroacetate ( $3.63 \mathrm{~mL}, 36 \mathrm{mmol}, 2 \mathrm{eq}$ ) was added dropwise, followed by $\mathrm{Et}_{3} \mathrm{~N}(10 \mathrm{~mL}, 72 \mathrm{mmol}, 4 \mathrm{eq})$. The reaction was allowed to proceed for 1 hour at RT. Solvent was removed in vacuo and the residue was dissolved in EtOAc, washed with $0.5 \mathrm{M} \mathrm{HCl}$, water, brine, and dried with $\mathrm{Mg}_{2} \mathrm{SO}_{4}$. EtOAc was removed by rotary evaporation and the product was crystalized in $\mathrm{CH}_{2} \mathrm{Cl}_{2}$ to afford 7 (4.22 g, 93\% yield) as fine white crystals. ${ }^{1} \mathrm{H}$ NMR (400 MHz, METHANOL-d $\left.d_{4}\right) \delta$ ppm $2.67(2 \mathrm{H}, \mathrm{t}, \mathrm{J}=7.63 \mathrm{~Hz}) 3.40(2 \mathrm{H}, \mathrm{t}, \mathrm{J}=7.43 \mathrm{~Hz}) 6.50$ (1 $\mathrm{H}$, dd, J=7.83, $1.96 \mathrm{~Hz}) 6.62(1 \mathrm{H}, \mathrm{d}, J=1.96 \mathrm{~Hz}) 6.66(1 \mathrm{H}, \mathrm{d}, J=7.83 \mathrm{~Hz}) .{ }^{13} \mathrm{C} \mathrm{NMR}(101 \mathrm{MHz}$, METHANOL- $\left.d_{4}\right) \delta$ ppm $33.83(1 \mathrm{C}, \mathrm{s}) 41.17(1 \mathrm{C}, \mathrm{s}) 114.96(1 \mathrm{C}, \mathrm{s}) 115.40(1 \mathrm{C}, \mathrm{s}) 117.51(1 \mathrm{C}$, s) 119.60 (1 C, s) 129.82 (1 C, s) 143.52 (1 C, s) 144.90 (1 C, s) 157.64 (1 C, s). HRMS $\mathrm{C}_{10} \mathrm{H}_{10} \mathrm{~F}_{3} \mathrm{NNaO}_{3}{ }^{+}$calc 272.0505 found 272.0481

N-(2-(2,2-dimethylbenzo[1,3]dioxol-5-yl)ethyl)-2,2,2-trifluoroacetamide 3.

2 (2 g, $8 \mathrm{mmol}, 1 \mathrm{eq}$ ) and 2,2-dimethoxypropane (3.9 mL, $32 \mathrm{mmol}, 4 \mathrm{eq})$ was add to $100 \mathrm{~mL}$ of toluene and heated to reflux to fully dissolve. $p$-Toluenesulfonic acid ( $68.8 \mathrm{mg}, 0.4 \mathrm{mmol}, 0.05 \mathrm{eq})$ was added and the solution was refluxed for 3 hours. Solvent was removed in vacuo and recrystallization in hexanes afforded 3 (1.82 g, 79\% yield) as dark crystalline solid. ${ }^{1} \mathrm{H}$ NMR (400 
MHz, CHLOROFORM- $d$ ) $\delta$ ppm $1.65(6 \mathrm{H}, \mathrm{s}) 2.76(2 \mathrm{H}, \mathrm{t}, \mathrm{J}=6.85 \mathrm{~Hz}) 3.54(2 \mathrm{H}, \mathrm{q}, \mathrm{J}=6.65 \mathrm{~Hz})$ 6.23 - $6.38(1 \mathrm{H}, \mathrm{m}) 6.53-6.58(2 \mathrm{H}, \mathrm{m}) 6.63-6.67(1 \mathrm{H}, \mathrm{m}) .{ }^{13} \mathrm{C}$ NMR $(101 \mathrm{MHz}, \mathrm{CHLOROFORM}-$ d) $\delta$ ppm $25.80(1 \mathrm{C}, \mathrm{s}) 34.67(1 \mathrm{C}, \mathrm{s}) 41.14(1 \mathrm{C}, \mathrm{s}) 108.31(1 \mathrm{C}, \mathrm{s}) 108.60(1 \mathrm{C}, \mathrm{s}) 118.05(1 \mathrm{C}$, s) $120.97(1 \mathrm{C}, \mathrm{s}) 130.41(1 \mathrm{C}, \mathrm{s}) 146.44(1 \mathrm{C}, \mathrm{s}) 147.91$ (1 C, s) 157.26 (1 C, s). HRMS $\mathrm{C}_{13} \mathrm{H}_{15} \mathrm{~F}_{3} \mathrm{NO}_{3}{ }^{+}$calc 290.0999 found 290.1028

2-(2,2-dimethylbenzo[1,3]dioxol-5-yl)ethan-1-amine 4.

3 (2.00 g, $6.92 \mathrm{mmol}, 1 \mathrm{eq})$ was dissolved into $\mathrm{MeOH}(50 \mathrm{~mL})$. LiOH (0.66 g, $27.68 \mathrm{mmol}, 4 \mathrm{eq})$ was dissolved into $25 \mathrm{~mL}$ of $\mathrm{H}_{2} \mathrm{O}$ and added dropwise. The resultant solution was stirred for 10 minutes at $\mathrm{RT}$. MeOH was removed in vacuo and the residue was dissolved in brine and extracted with EtOAc, dried with $\mathrm{MgSO}_{4}$, and concentrated to give $4(1.30 \mathrm{~g}, 98 \%)$ as a dark brown viscous oil. ${ }^{1} \mathrm{H}$ NMR (400 MHz, CHLOROFORM- $\left.d\right) \delta$ ppm $1.64(6 \mathrm{H}, \mathrm{d}, \mathrm{J}=1.17 \mathrm{~Hz}) 2.63(2 \mathrm{H}, \mathrm{t}, \mathrm{J}=6.65$ $\mathrm{Hz}) 2.89(2 \mathrm{H}, \mathrm{t}, \mathrm{J}=6.65 \mathrm{~Hz}) 6.55-6.66(3 \mathrm{H}, \mathrm{m}) .{ }^{13} \mathrm{C}$ NMR $(101 \mathrm{MHz}, \mathrm{CHLOROFORM}-d) \delta \mathrm{ppm}$ $25.80(2 \mathrm{C}, \mathrm{s}) 39.58(1 \mathrm{C}, \mathrm{s}) 43.60(1 \mathrm{C}, \mathrm{s}) 107.95(1 \mathrm{C}, \mathrm{s}) 108.86(1 \mathrm{C}, \mathrm{s}) 117.57(1 \mathrm{C}, \mathrm{s}) 120.98$ $(1 \mathrm{C}, \mathrm{s}) 132.73(1 \mathrm{C}, \mathrm{s}) 145.76(1 \mathrm{C}, \mathrm{s}) 147.48(1 \mathrm{C}, \mathrm{s})$. HRMS $\mathrm{C}_{11} \mathrm{H}_{16} \mathrm{NO}_{2}{ }^{+}$calc 194.1176 found 194.1186

N-(2-(2,2-dimethylbenzo[1,3]dioxol-5-yl)ethyl)-4-nitrobenzenesulfonamide 5.

4 (730 mg, $3.7 \mathrm{mmol}, 1.1 \mathrm{eq}$ ) and 4-nitrobenzenesulfonyl chloride (760 mg, $3.4 \mathrm{mmol}, 1 \mathrm{eq}$ ) were dissolved in $10 \mathrm{~mL} \mathrm{CH} \mathrm{Cl}_{2}$, placed under $\mathrm{N}_{2}$, and cooled to $0{ }^{\circ} \mathrm{C}$. $\mathrm{Et}_{3} \mathrm{~N}(0.514 \mathrm{~mL}, 3.7 \mathrm{mmol}, 1.1$ eq) was added dropwise and the reaction was stirred at $0^{\circ} \mathrm{C}$ for 5 minutes and allowed to warm to $\mathrm{RT}$ and stirred for an additional 15 minutes. $15 \mathrm{~mL}$ of sat. $\mathrm{NH}_{4} \mathrm{Cl}$ was added and the reaction mixture was extracted with $\mathrm{CH}_{2} \mathrm{Cl}_{2}$, washed with brine, dried with $\mathrm{MgSO}_{4}$, and concentrated in vacuo to afford $5(1.25 \mathrm{~g}, 97 \%)$ as a yellow solid. ${ }^{1} \mathrm{H}$ NMR (400 MHz, CHLOROFORM- $d$ ) $\delta \mathrm{ppm}$ $1.63(6 \mathrm{H}, \mathrm{s}) 2.67(2 \mathrm{H}, \mathrm{t}, \mathrm{J}=6.65 \mathrm{~Hz}) 3.17$ - $3.27(2 \mathrm{H}, \mathrm{m}) 4.61(1 \mathrm{H}, \mathrm{br}$. s.) 6.37 - $6.49(2 \mathrm{H}, \mathrm{m})$ $6.59(1 \mathrm{H}, \mathrm{d}, J=7.83 \mathrm{~Hz}) 7.92-8.00(2 \mathrm{H}, \mathrm{m}) 8.27-8.35(2 \mathrm{H}, \mathrm{m}) .{ }^{13} \mathrm{C} \mathrm{NMR}(101 \mathrm{MHz}$, CHLOROFORM- $d$ ) $\delta$ ppm 25.79 (2 C, s) 35.47 (1 C, s) 44.41 (1 C, s) 108.31 (1 C, s) 108.53 (1 C, s) $118.13(1 \mathrm{C}, \mathrm{s}) 121.07$ (1 C, s) 124.32 (2 C, s) $128.22(2 \mathrm{C}, \mathrm{s}) 129.91$ (1 C, s) 145.83 (1 C, s) $146.50(1 \mathrm{C}, \mathrm{s}) 147.86(1 \mathrm{C}, \mathrm{s}) 149.99(1 \mathrm{C}, \mathrm{s})$. HRMS $\mathrm{C}_{17} \mathrm{H}_{17} \mathrm{~N}_{2} \mathrm{O}_{6} \mathrm{~S}^{-}$calc 377.0813 found 377.1297

$N$-(2-(2,2-dimethylbenzo[1,3]dioxol-5-yl)ethyl)-4-nitro- $N$-(prop-2-yn-1-yl)benzenesulfonamide 6.

5 (1.2 g, $3.17 \mathrm{mmol}, 1 \mathrm{eq})$ and potassium carbonate $(876 \mathrm{mg}, 6.35 \mathrm{mmol}, 2 \mathrm{eq})$ were dissolved in $50 \mathrm{~mL}$ of acetone under $\mathrm{N}_{2}$. Propargyl bromide solution $80 \mathrm{wt}$. \% in toluene $(.374 \mathrm{~mL}, 3.8 \mathrm{mmol}$, $1.2 \mathrm{eq}$ ) was added dropwise and the resultant solution was refluxed for 12 hours. Solvent was removed in vacuo and the residue was dissolved in $\mathrm{H}_{2} \mathrm{O}$ and extracted with $\mathrm{CH}_{2} \mathrm{Cl}_{2}$, washed with brine, dried with $\mathrm{MgSO}_{4}$, and subjected to column chromatography hexanes:EtOAc v/v gradient of $4: 1$ to $1: 1)$ to afford $6(1.27 \mathrm{~g}, 96 \%)$ as a dark amber oil. ${ }^{1} \mathrm{H}$ NMR $(400 \mathrm{MHz}, \mathrm{CHLOROFORM-}$ d) $\delta$ ppm 1.62 - $1.66(6 \mathrm{H}, \mathrm{m}) 2.05(1 \mathrm{H}, \mathrm{d}, \mathrm{J}=2.74 \mathrm{~Hz}) 2.81(2 \mathrm{H}, \mathrm{dd}, \mathrm{J}=8.41,6.85 \mathrm{~Hz}) 3.39(2 \mathrm{H}$, dd, J=8.22, $7.04 \mathrm{~Hz}) 4.14(2 \mathrm{H}, \mathrm{d}, \mathrm{J}=2.35 \mathrm{~Hz}) 6.53-6.66(3 \mathrm{H}, \mathrm{m}) 7.95-8.04(2 \mathrm{H}, \mathrm{m}) 8.26-8.35$ $(2 \mathrm{H}, \mathrm{m}){ }^{13} \mathrm{C}$ NMR (101 MHz, CHLOROFORM- $d$ ) $\delta$ ppm 25.78 (2 C, s) 34.41 (1 C, s) 36.86 (1 C, s) $48.30(1 \mathrm{C}, \mathrm{s}) 74.41(1 \mathrm{C}, \mathrm{s}) 75.89(1 \mathrm{C}, \mathrm{s}) 108.25(1 \mathrm{C}, \mathrm{s}) 108.85(1 \mathrm{C}, \mathrm{s}) 117.94(1 \mathrm{C}, \mathrm{s})$ 
$121.06(1 \mathrm{C}, \mathrm{s}) 124.06(1 \mathrm{C}, \mathrm{s}) 128.87(1 \mathrm{C}, \mathrm{s}) 130.49(1 \mathrm{C}, \mathrm{s}) 144.70(1 \mathrm{C}, \mathrm{s}) 146.29(1 \mathrm{C}, \mathrm{s})$ $147.64(1 \mathrm{C}, \mathrm{s}) 150.07(1 \mathrm{C}, \mathrm{s})$. HRMS $\mathrm{C}_{20} \mathrm{H}_{19} \mathrm{~N}_{2} \mathrm{O}_{6} \mathrm{~S}^{-}$calc 415.0969 found 415.2538

N-(2-(2,2-dimethylbenzo[1,3]dioxol-5-yl)ethyl)prop-2-yn-1-amine 7.

Potassium hydroxide $(328 \mathrm{mg}, 5.8 \mathrm{mmol}, 2$ eq) predissolved into a $10 \mathrm{M}$ aq. solution and thiophenol $(0.654 \mathrm{~mL}, 5.8 \mathrm{mmol}, 2 \mathrm{eq})$ were combined in $25 \mathrm{~mL}$ of $\mathrm{CH}_{3} \mathrm{CN}$ and cooled to $0{ }^{\circ} \mathrm{C} .6$ (1.22 g, $2.9 \mathrm{mmol}, 1 \mathrm{eq}$ ) dissolved in $25 \mathrm{~mL}$ of $\mathrm{CH}_{3} \mathrm{CN}$ was added. The solution was heated to 50 ${ }^{\circ} \mathrm{C}$ for 40 minutes. The reaction was quenched with $\mathrm{H}_{2} \mathrm{O}$, extracted with $\mathrm{CH}_{2} \mathrm{Cl}_{2}$, washed with brine, dried with $\mathrm{MgSO}_{4}$, and subjected to column chromatography (hexanes:EtOAc v/v gradient of $4: 1$ to $1: 1)$ to afford 7 (338 mg, $50 \%)$ as a yellow oil. ${ }^{1} \mathrm{H}$ NMR $(400 \mathrm{MHz}, \mathrm{CHLOROFORM-d)} \delta$ ppm $1.62-1.66(6 \mathrm{H}, \mathrm{m}) 2.16-2.21(1 \mathrm{H}, \mathrm{m}) 2.71(2 \mathrm{H}, \mathrm{t}, \mathrm{J}=7.04 \mathrm{~Hz}) 2.90(2 \mathrm{H}, \mathrm{t}, \mathrm{J}=7.04 \mathrm{~Hz})$ 3.39 - $3.45(2 \mathrm{H}, \mathrm{m}) 6.57-6.66(3 \mathrm{H}, \mathrm{m}) .{ }^{13} \mathrm{C}$ NMR (101 MHz, CHLOROFORM- $\left.d\right) \delta$ ppm $25.83(2$ C, s) $35.72(1 \mathrm{C}, \mathrm{s}) 38.04(1 \mathrm{C}, \mathrm{s}) 49.87(1 \mathrm{C}, \mathrm{s}) 71.44(1 \mathrm{C}, \mathrm{s}) 81.84(1 \mathrm{C}, \mathrm{s}) 108.01(1 \mathrm{C}, \mathrm{s})$ $108.78(1 \mathrm{C}, \mathrm{s}) 117.61(1 \mathrm{C}, \mathrm{s}) 120.88(1 \mathrm{C}, \mathrm{s}) 132.66(1 \mathrm{C}, \mathrm{s}) 145.81(1 \mathrm{C}, \mathrm{s}) 147.50(1 \mathrm{C}, \mathrm{s})$. HRMS $\mathrm{C}_{14} \mathrm{H}_{18} \mathrm{NO}_{2}{ }^{+}$calc 232.1332 found 232.1296

\section{4-(2-(prop-2-yn-1-ylamino)ethyl)benzene-1,2-diol 8a (DA $\left.{ }^{\text {yne }}\right)$.}

7 (19.5 mg, $0.11 \mathrm{mmol}, 1 \mathrm{eq})$ was dissolved in $\mathrm{CHCl}_{3}(2 \mathrm{~mL})$ and $\mathrm{H}_{2} \mathrm{O}(50 \mu \mathrm{L})$. TFA $(400 \mu \mathrm{L})$ was added and the resultant solution was stirred under $\mathrm{Ag}$ at $\mathrm{RT}$ overnight. Solvent was removed in vacuo followed by the addition of $1 \mathrm{~mL}$ of $0.1 \mathrm{~N} \mathrm{HCl}$ in THF which was also removed by rotatory evaporation. The reside was then dissolved aqueous $0.1 \mathrm{~N} \mathrm{HCl}$ and lyophilizatied to afford $8 \mathrm{a}$ (DA $\left.{ }^{\text {yne }}\right)\left(21 \mathrm{mg}\right.$, quant.) as white solid. ${ }^{1} \mathrm{H}$ NMR $\left(400 \mathrm{MHz}, \mathrm{METHANOL}-d_{4}\right) \delta \mathrm{ppm} 2.84(2 \mathrm{H}, \mathrm{t}$, $J=7.63 \mathrm{~Hz}) 3.16-3.22(1 \mathrm{H}, \mathrm{m}) 3.27(2 \mathrm{H}, \mathrm{t}, \mathrm{J}=7.83 \mathrm{~Hz}) 3.92(2 \mathrm{H}, \mathrm{d}, \mathrm{J}=2.74 \mathrm{~Hz}) 6.55-6.62(1 \mathrm{H}$, m) $6.70(1 \mathrm{H}, \mathrm{d}, J=1.96 \mathrm{~Hz}) 6.74(1 \mathrm{H}, \mathrm{d}, J=7.83 \mathrm{~Hz}){ }^{13} \mathrm{C}$ NMR $\left(101 \mathrm{MHz}\right.$, METHANOL- $\left.d_{4}\right) \delta \mathrm{ppm}$ $32.89(1 \mathrm{C}, \mathrm{s}) 37.72(1 \mathrm{C}, \mathrm{s}) 74.81(1 \mathrm{C}, \mathrm{s}) 79.51(1 \mathrm{C}, \mathrm{s}) 117.09(1 \mathrm{C}, \mathrm{s}) 117.13(1 \mathrm{C}, \mathrm{s}) 121.35$ $(1 \mathrm{C}, \mathrm{s}) 129.06(1 \mathrm{C}, \mathrm{s}) 146.02(1 \mathrm{C}, \mathrm{s}) 147.12(1 \mathrm{C}, \mathrm{s}) . \mathrm{HRMS} \mathrm{C}{ }_{11} \mathrm{H}_{14} \mathrm{NO}_{2}{ }^{+}$calc 192.1019 found 192.1078 
NMR Spectra

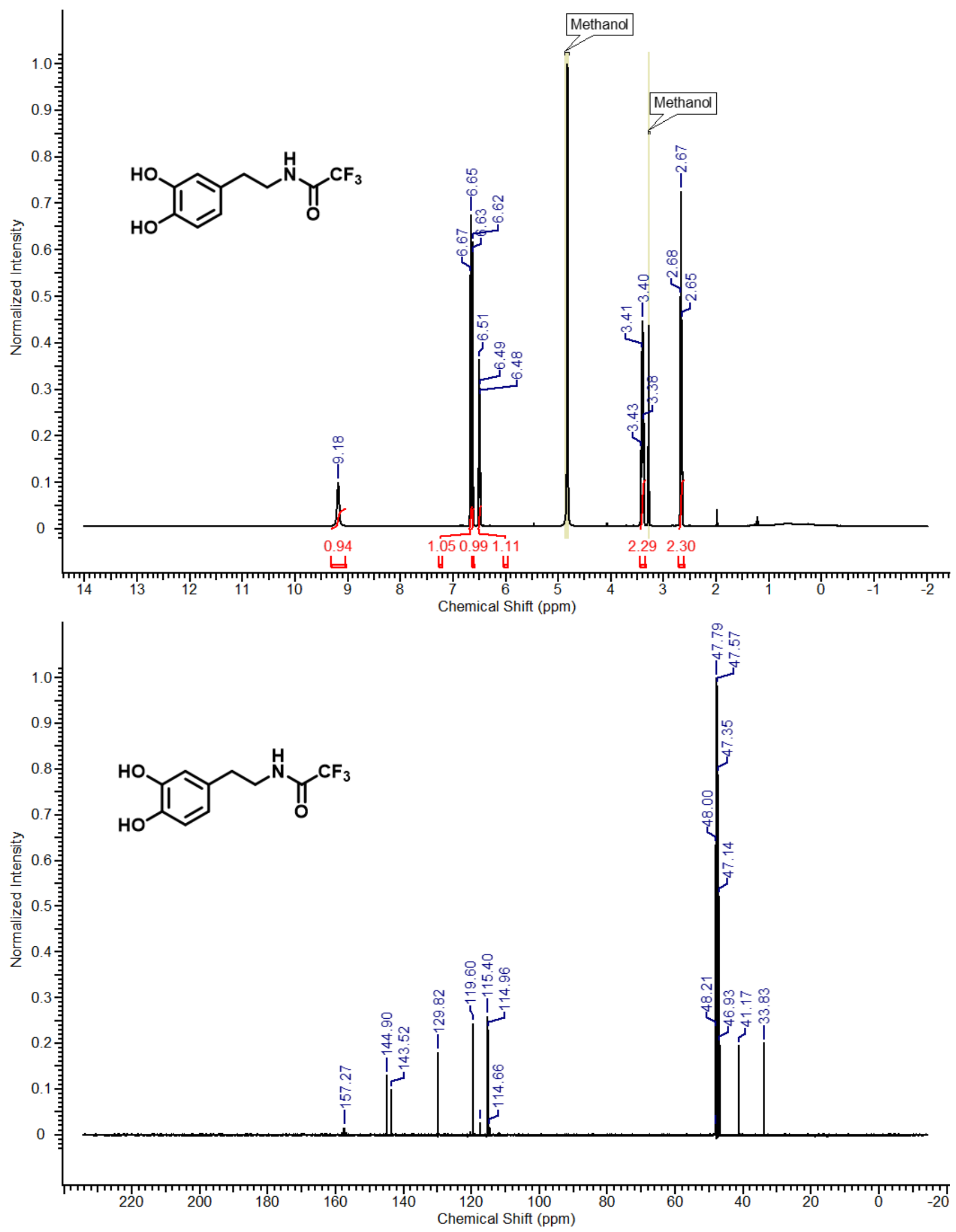



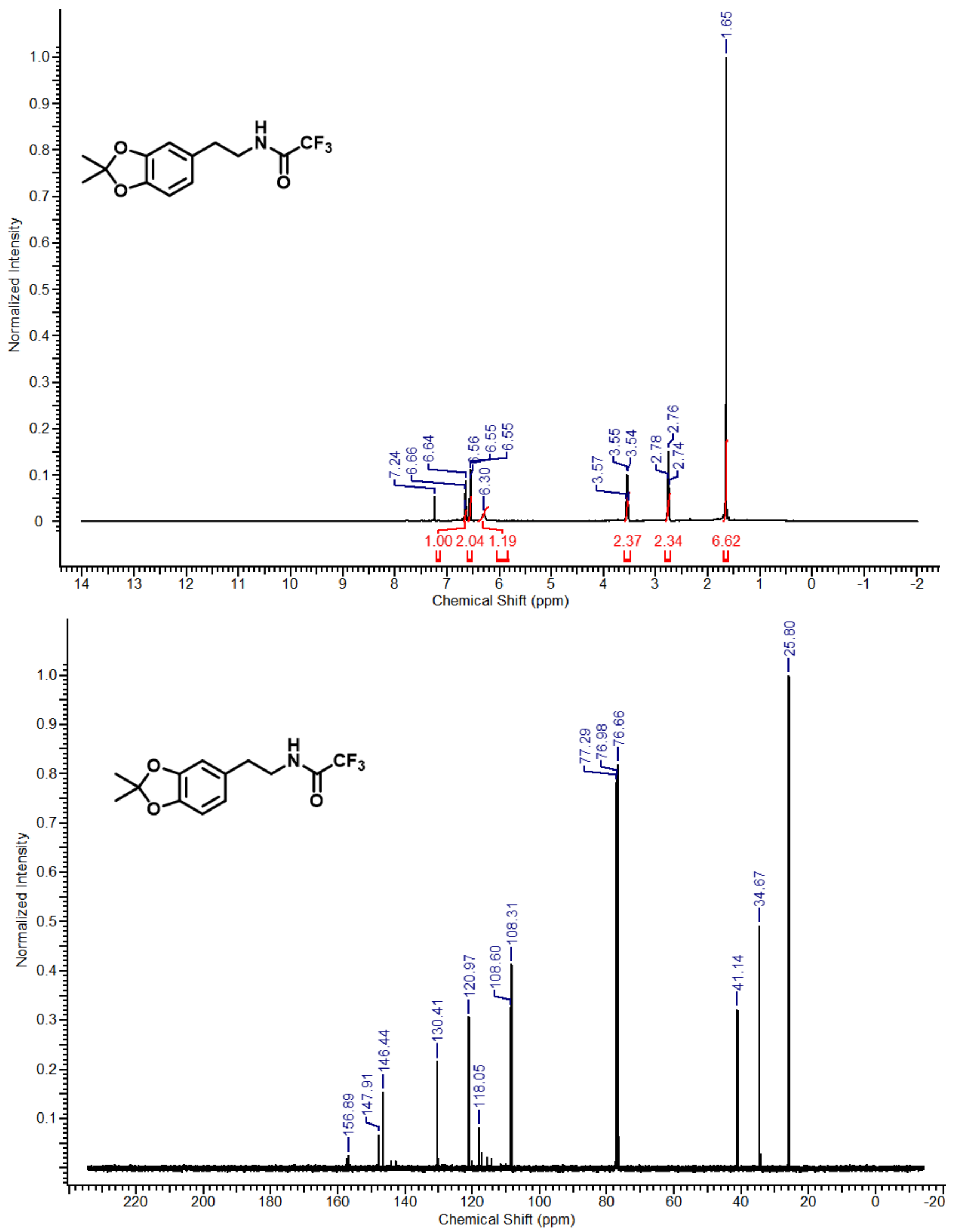


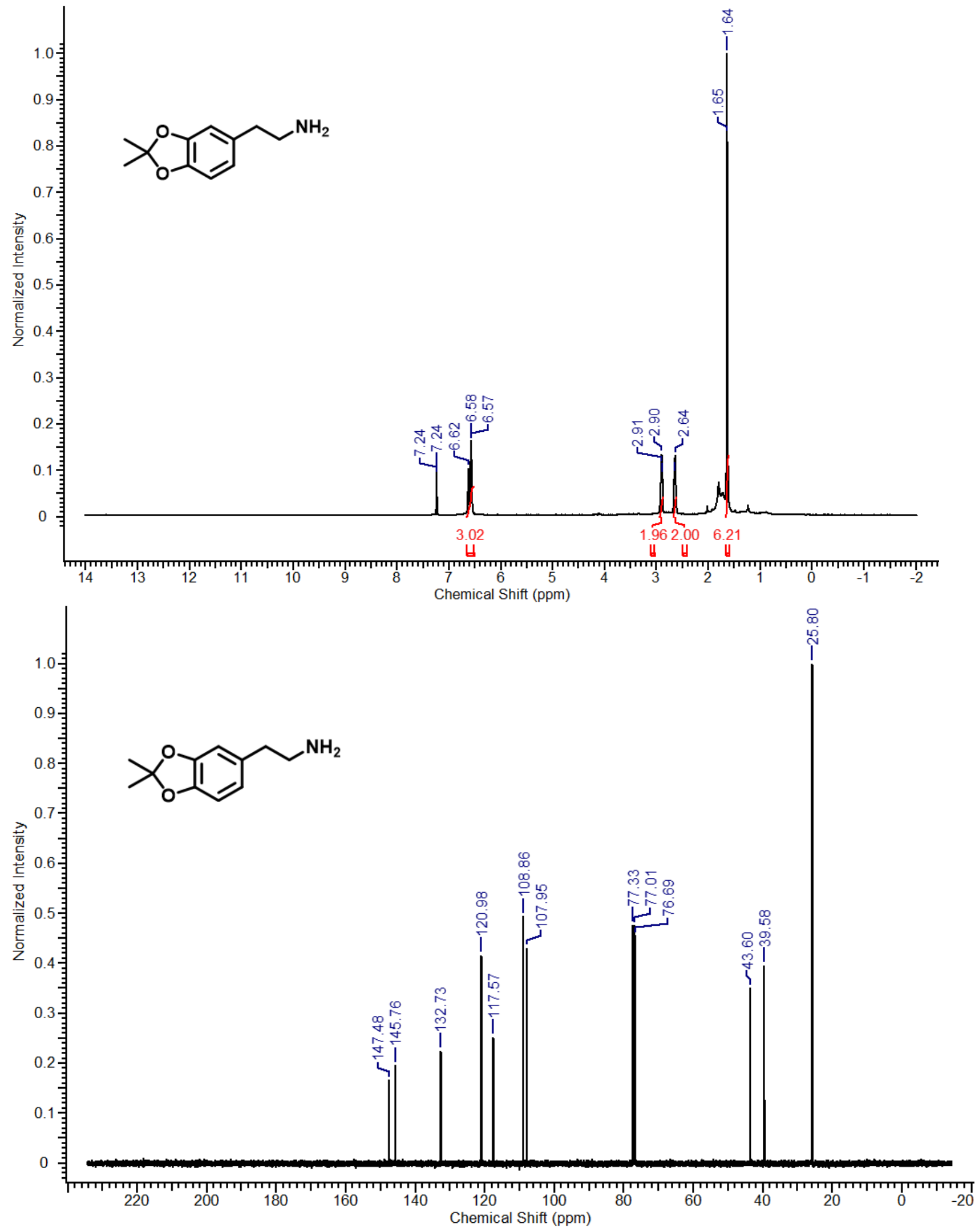



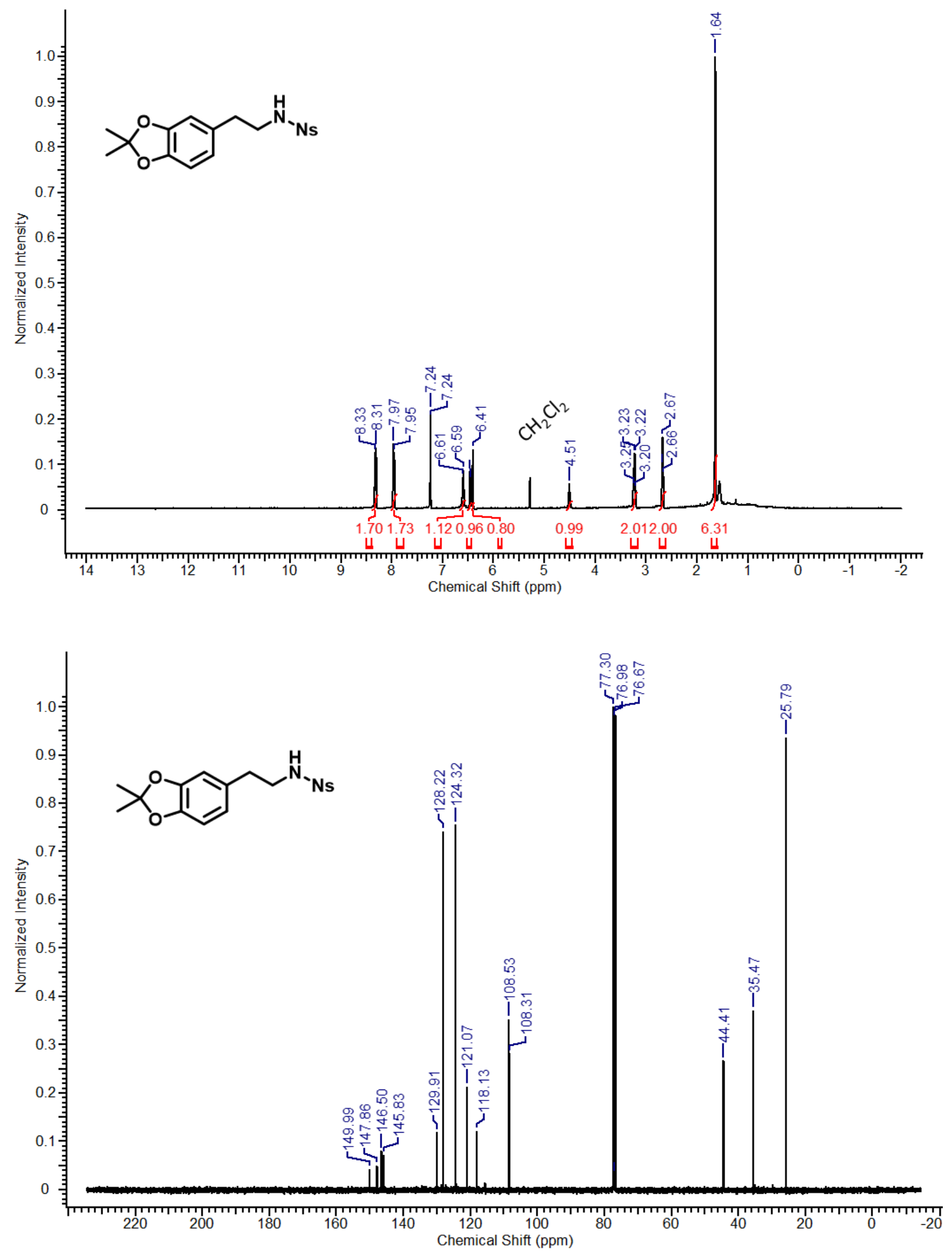

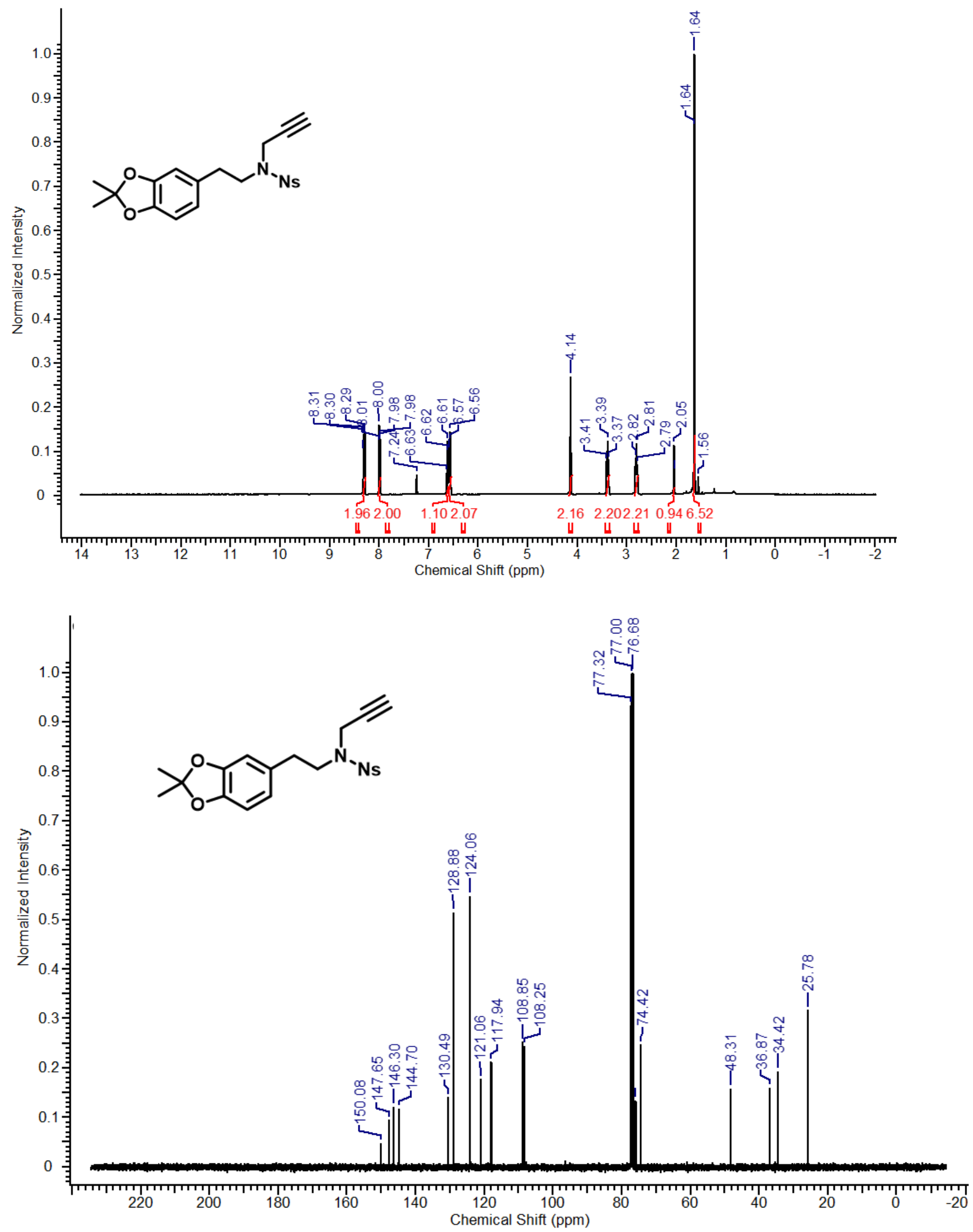

19 

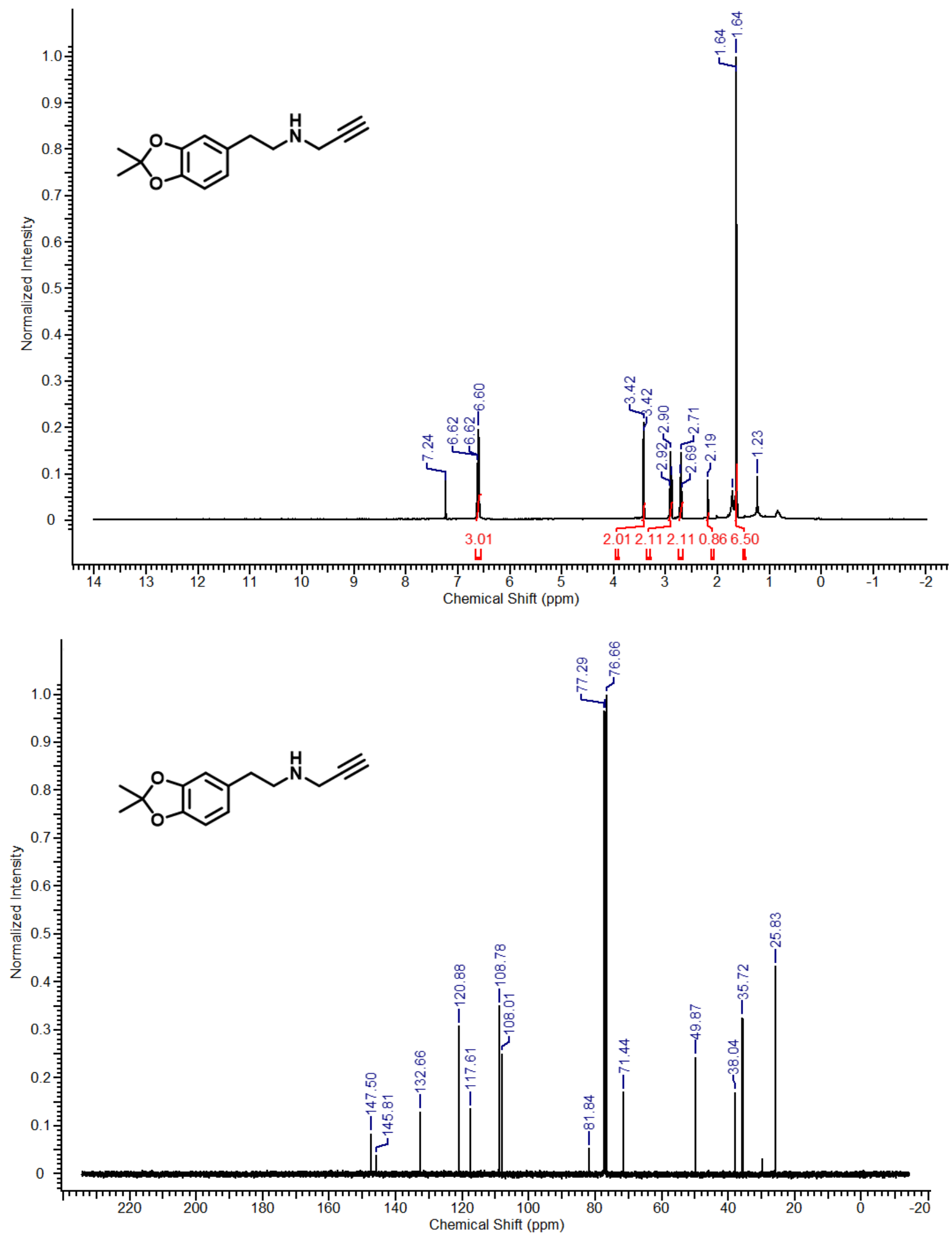

20 

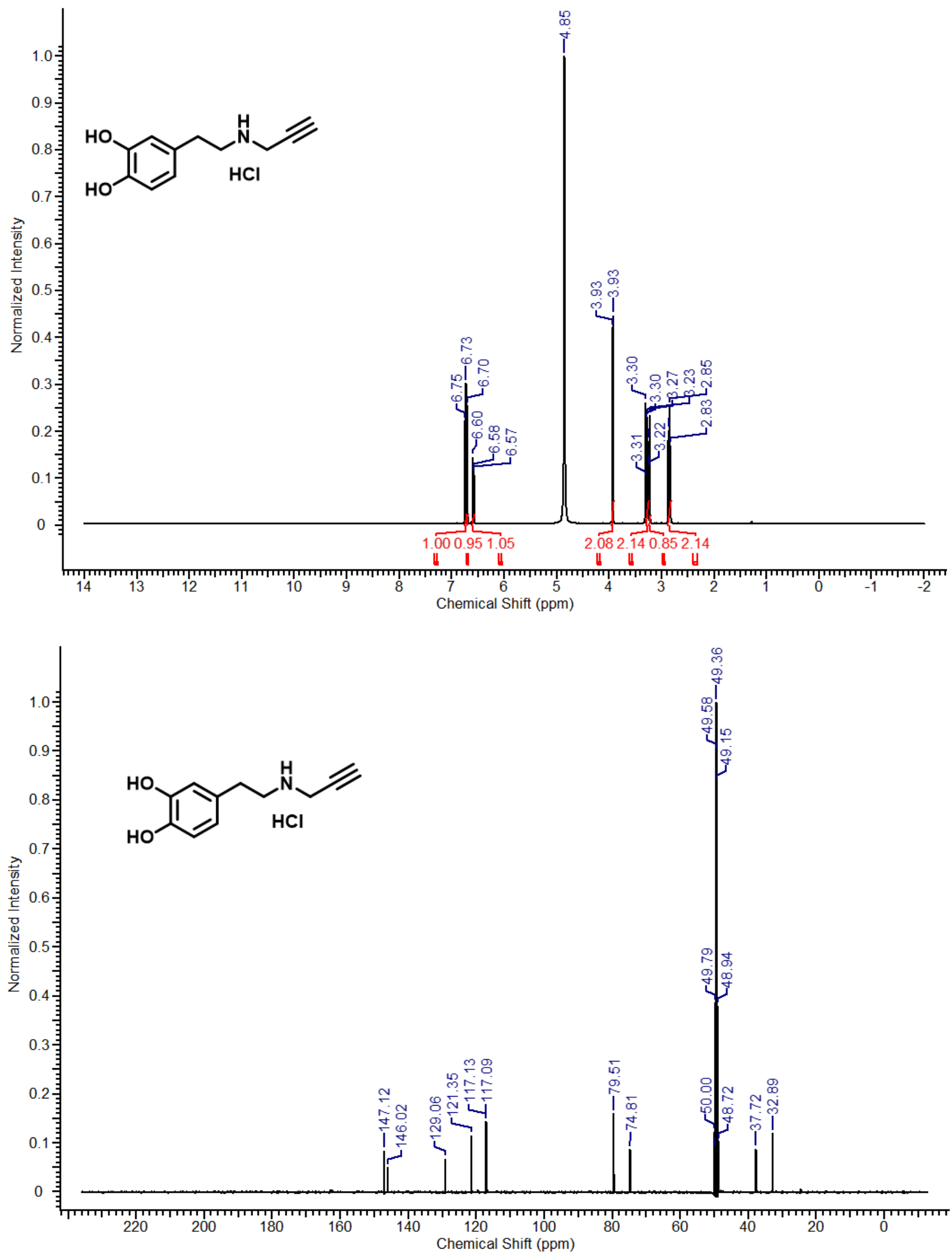


\section{References}

1. Paz, M. A.; Flückiger, R.; Boak, A.; Kagan, H. M.; Gallop, P. M., J. Biol. Chem. 1991, 266, 689-692.

2. Gowda, G. A. N.; Abell' L.; Lee, C. F.; Tian R.; Raftery, D., Anal. Chem. 2016, 88, 2399-2405. 